Article

\title{
Phage Displayed Domain Antibodies (dAb) for Detection of Allergenic Pistachio Proteins in Foods
}

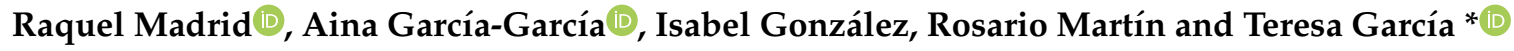 \\ Departamento de Nutrición y Ciencia de los Alimentos, Facultad de Veterinaria, \\ Universidad Complutense de Madrid, 28040 Madrid, Spain; raqmad01@ucm.es (R.M.); \\ ainagarcia@ucm.es (A.G.-G.); gonzalzi@ucm.es (I.G.); rmartins@ucm.es (R.M.) \\ * Correspondence: tgarcia@ucm.es; Tel.: +34-91-394-3747
}

Received: 22 July 2020; Accepted: 1 September 2020; Published: 3 September 2020

check for updates

\begin{abstract}
Pistachio nuts (Pistacia vera) have been consumed by past and present-day civilizations because of their organoleptic characteristics and potential health benefits. However, they can also produce moderate to severe IgE-mediated reactions in allergic individuals. In this work, we report the isolation of the first recombinant antibodies against pistachio nut, produced without animal immunization, to be used in immunoassays for detection of allergenic pistachio in food products. Several phage display biopanning strategies were evaluated to screen the human-based domain antibody library $(\mathrm{dAb})$ in search for pistachio-specific probes. The clone producing the PVF4 phage- $\mathrm{dAb}$ was finally selected, and it does not cross-react with cashew despite the phylogenetic proximity with pistachio. Western blot and matrix-assisted laser desorption/ionization tandem mass spectrometry (MALDI-TOF/TOF) analysis demonstrated that this clone recognised a unique band of $\sim 22 \mathrm{kDa}$ related to the basic subunit of pistachio 11S globulin (allergen Pis v 2). The PVF4 phage-dAb allowed detection of pistachio in a food matrix with a limit of detection (LOD) of $3983 \mathrm{mg} \mathrm{kg}^{-1}$ in an indirect phage-enzyme-linked immunosorbent assay (ELISA). The ELISA method developed was used to assess applicability of the PVF4 phage-dAb for analysis of 77 commercial food products.
\end{abstract}

Keywords: phage-ELISA; 11S globulin; food analysis; domain antibody (dAb); recombinant antibody; pistachio detection; food allergen detection

\section{Introduction}

Pistachio nuts (Pistacia vera) have been part of the human diet since prehistoric times and have been consumed because of their organoleptic characteristics and potential health benefits [1]. However, they can also produce moderate to severe IgE-mediated reactions in allergic individuals. Moreover, pistachio-allergic patients often report allergy to cashews, probably due to the close relation of these two members of the Anacardiaceae family [2,3]. Until now, the allergen nomenclature sub-committee of the World Health Organization and International Union of Immunological Societies (WHO/IUIS) has recognised five allergenic proteins for pistachio nut, named Pis v 1, Pis v 2, Pis v 3, Pis v 4, and Pis v 5 [4-6].

Pistachio-allergic patients should thoroughly read product labelling, understand it, and avoid products with allergen warnings [7]. Moreover, to ensure compliance with food labelling regulations and provide accurate information to allergic consumers, it is key to establish an effective risk assessment of allergens in the food industry, including assessment of undeclared allergens in raw materials purchased from suppliers. This requires rapid, specific, and sensitive methods to detect allergens in raw and processed foods [8].

There are several genetic and immunological methods available for the detection of pistachio in food products [9-11]. Immunoassays are the most widely used methods for the detection of pistachio in foods, and there are some commercial kits available. However, all the immunoassays currently 
available for this purpose rely on the use of polyclonal or monoclonal antibodies raised in animals. Current international regulations on animal welfare (European Directive 2010/63/EU) firmly encourage the development of alternatives based on the principle of the 'Three Rs': to replace, reduce, and refine the use of animals in research and testing procedures [12]. Therefore, there is a need for alternatives to the use of experimental animals to obtain antibodies capable to detect pistachio allergens in food products. The development of immunoassays based on recombinant antibodies that do not depend on in vivo immunizations is still incipient and provides a novel and promising alternative for the detection of food allergens.

Using phage display technology, recombinant antibodies of defined specificity and constant amino acid sequence can be produced without animal immunization for use in immunoassays. This method uses libraries of recombinant phage antibodies that display functional antibody fragments, like single-chain variable fragments $(\mathrm{scFv})$ or heavy chain variable domains $(\mathrm{VH})$, in their surface. The application of phage display technology for the detection of food allergens has significant potential, but it is still limited to the detection of some allergenic tree nuts with recombinant scFvs $[13,14]$. Compared to other antibody fragments, like scFv and Fab, VH single domain antibodies or nanobodies have a smaller size $(14 \mathrm{kDa})$, higher solubility and stability, and excellent tissue penetration in vivo. Moreover, they can be genetically linked or chemically conjugated to different molecules to facilitate their use in immunoassays or as therapeutic agents [15]. Isolation of phage-antibody fragments of the desired specificity is achieved by an iterative biopanning procedure with the immobilised antigen [16].

In this work, we report the isolation of recombinant antibodies against pistachio nut from the human based domain antibody library $(\mathrm{dAb})$ by an iterative affinity selection procedure, avoiding animal immunization. We also describe an indirect phage-enzyme-linked immunosorbent assay (ELISA) that allows for the detection of pistachio in commercial food products.

\section{Materials and Methods}

\subsection{Materials and Chemicals}

The protein extraction buffer consisted of $0.035 \mathrm{M}$ phosphate solution containing $1 \mathrm{M} \mathrm{NaCl}$, $\mathrm{pH}$ 7.5. Phosphate-buffered saline (PBS) composition is $0.01 \mathrm{M}$ phosphate buffer, $0.0027 \mathrm{M}$ potassium chloride, and $0.137 \mathrm{M}$ sodium chloride, $\mathrm{pH}$ 7.4. Milk phosphate-buffered saline (MPBS) contains 1\% skimmed milk powder in PBS. PBST is PBS containing 0.01\% Tween 20. Tryptone, yeast extract and European bacteriological agar were purchased from Laboratorios Conda (Madrid, Spain). The $2 \times \mathrm{TY}$ broth is $16 \mathrm{~g} \mathrm{~L}^{-1}$ tryptone, $10 \mathrm{~g} \mathrm{~L}^{-1}$ yeast extract, and $5 \mathrm{~g} \mathrm{~L}^{-1} \mathrm{NaCl}$. TYE agar is $15 \mathrm{~g} \mathrm{~L}^{-1}$ bacto-agar, $10 \mathrm{~g} \mathrm{~L}^{-1}$ tryptone, $5 \mathrm{~g} \mathrm{~L}^{-1}$ yeast extract and $8 \mathrm{~g} \mathrm{~L}^{-1} \mathrm{NaCl}$. Sample buffer is $0.5 \mathrm{M}$ Tris- $\mathrm{HCl}$ buffer, $\mathrm{pH} 6.8,10 \%$ SDS, $20 \%$ glycerol, $0.5 \%$ bromophenol blue as the tracking dye, and $5 \% \beta$-mercaptoethanol. BlueSafe to stain proteins in an SDS-PAGE was provided by NZytech (Lisbon, Portugal). Transfer buffer consisted of $0.025 \mathrm{~mol} \mathrm{~L}^{-1}$ Tris, $\mathrm{pH} 8.3,0.192 \mathrm{~mol} \mathrm{~L}^{-1}$ glycine, and $200 \mathrm{~mL} \mathrm{~L}^{-1}$ methanol. Unless otherwise stated, chemicals were provided by Sigma-Aldrich (Merck KGaA, Darmstadt, Germany). Horseradish peroxidase (HRP)/anti-M13 monoclonal mouse antibody was purchased from GE Healthcare (GE Healthcare UK Ltd., Amersham, UK).

The human domain antibody library (dAb), M13 K07 helper phage and Escherichia coli TG1 strain (K12 $\Delta$ (lac-proAB) supE thi hsdD5/F' traD36 proA $^{+} \mathrm{B}$ lacl ${ }^{q}$ lacZ $\left.\Delta \mathrm{M} 15\right)$ were obtained from Source BioScience (Nottingham, UK). This is a single-domain antibody library based on a VH framework (V3-23/D47) that was developed by Daniel Christ at the MRC Laboratory of Molecular Biology (Cambridge, UK) [17]. Diversity was introduced into the antigen binding domains by polymerase chain reaction (PCR) mutagenesis into the three complementarity-determining regions (CDR1, CDR2 and CDR3). The library is constructed in the ampicillin resistant phagemid vector pR2 (MYC VSV tag) with a size of $3 \times 10^{9}$. The repertoire has been engineered to withstand heat-induced aggregation on phage and has been displayed as a fusion with the terminal phage gene III protein. 


\subsection{Sample Preparations}

A wide variety of tree nuts, plant and animal species (Table 1), commercial food products and commercial pistachios (raw and roasted) from different origins (the United States, Iran, and Spain) were analysed. The samples were acquired in different stores and local markets in Madrid (Spain). All food samples (5 g) were finely ground and stored in screw capped vials at $-20{ }^{\circ} \mathrm{C}$.

Table 1. List of heterologous species analysed in the indirect phage enzyme-linked immunosorbent assay (ELISA).

\begin{tabular}{|c|c|c|}
\hline \multicolumn{3}{|l|}{ Nuts } \\
\hline Almond (Prunus dulcis) & Hazelnut (Corylus avellana) & Pecan nut (Carya illinoinensis) \\
\hline Brazil nut (Bertholletia excels) & Macadamia (Macadamia integrifolia) & Pine nut (Pinus pinea) \\
\hline Cashew nut (Anacardium occidentale) & Peanut (Arachis hypogaea) & Walnut (Juglans regia) \\
\hline \multicolumn{3}{|l|}{ Chesnut (Castanea sativa) } \\
\hline \multicolumn{3}{|l|}{ Vegetal Species } \\
\hline Anise (Pimpinella anisum) & Garlic (Allium sativum) & Pinto bean (Phaseolus coccineus) \\
\hline Apple (Malus domestica) & Green peppers (Capsicum annuum) & Plum (Prunus domestica) \\
\hline Apricot (Prunus armeniaca) & Kiwifruit (Actinidia deliciosa) & Pomegranate (Punica granatum) \\
\hline Asparagus (Asparagus officinalis) & Lentil (Lens culinaris) & Poppy seed (Papaver rhoeas) \\
\hline Aubergine (Solanum melongena) & Lupin bean (Lupinus albus) & Prune (Prunus domestica) \\
\hline Banana (Musa acuminate) & Maize (Zea mays) & Pumpkin seed (Cucurbita maxima) \\
\hline Barley (Hordeum vulgare) & Mandarin orange (Citrus reticulate) & Quinoa (Chenopodium quinoa) \\
\hline Bean (Phaseolus vulgaris) & Melon (Cucumis melo) & Rice (Oryza sativa) \\
\hline Blackberry (Rubus ulmifolius) & Oats (Avena sativa) & Rye (Secale cereal) \\
\hline Brown sugar (Saccharum officinarum) & Olive (Olea europaea) & Sesame (Sesamum indicum) \\
\hline Carrot (Daucus carota) & Onion (Allium cepa) & Soya (Glycine max) \\
\hline Cherry (Prunus avium) & Orange (Citrus sinensis) & Sunflower seed (Helianthus annuus) \\
\hline Chia (Salvia hispánica) & Paprika (Capsicum annuum) & Tiger nut (Cyperus esculentus) \\
\hline Chickpea (Cicer arietinum) & Pea (Pisum sativum) & Tomato (Solanum lycopersicum) \\
\hline Cinnamon (Cinnamomum verum) & Peach (Prunus persica) & Vanilla (Vanilla planifolia) \\
\hline Cocoa (Theobroma cacao) & Pear (Pyrus communis L.) & Wheat (Triticum aestivum) \\
\hline Flaxseed (Linum usitatissimum) & Pineapple (Ananas comosus) & Courgette (Cucurbita pepo) \\
\hline \multicolumn{3}{|l|}{ Animal Species } \\
\hline Beef (Bos Taurus) & Salmon (Salmo salar) & Chicken (Gallus gallus domesticus) \\
\hline Egg (Gallus gallus domesticus) & Milk (Bos Taurus) & Pork (Sus scrofa domestica) \\
\hline
\end{tabular}

Pistachio, cashew, and peanut were defatted to be used in some of the biopanning procedures. The nut (5 g) was finely ground in an analytical mill (IKA ${ }^{\circledR}$ A11, Staufen, Germany), and $0.8 \mathrm{~g}$ of nut powder was dissolved in $20 \mathrm{~mL}$ of acetone, vigorously shaken for $1 \mathrm{~min}$, and centrifuged at $10,000 \times g$ for $30 \mathrm{~min}$. Then, the supernatant was removed, and the process was repeated four times. Finally, the defatted sediment was dried for $24 \mathrm{~h}$ and stored in screw capped vials at $-20{ }^{\circ} \mathrm{C}$.

Binary mixtures $\left(10^{5}\right.$ to $\left.100 \mathrm{mg} \mathrm{kg}^{-1}\right)$ of roasted pistachio in corn flour were prepared using an IKA A11 analytical mill to evaluate the sensitivity of the assay and to be used as reference samples. Concentration of $10^{5} \mathrm{mg} \mathrm{kg}^{-1}$ was prepared by adding $5 \mathrm{~g}$ of ground pistachios to $45 \mathrm{~g}$ of corn flour. Concentrations of $10^{4}, 10^{3}$, and $100 \mathrm{mg} \mathrm{kg}^{-1}$ were prepared by adding $5 \mathrm{~g}$ of the corresponding binary mixture to $45 \mathrm{~g}$ of corn flour. Concentrations of $7.5 \times 10^{4}, 5 \times 10^{4}, 2.5 \times 10^{4}, 2 \times 10^{4}, 5 \times 10^{3}$, and $500 \mathrm{mg} \mathrm{kg}^{-1}$ were prepared in a similar way. All the mixtures were stored in screw capped vials at $-20{ }^{\circ} \mathrm{C}$.

Protein extracts from binary mixtures, tree nuts or food products were prepared by mixing $0.2 \mathrm{~g}$ sample with $1.2 \mathrm{~mL}$ of protein extraction buffer, and the mixture was shaken for $10 \mathrm{~min}$ at room temperature in a vertical rotator (HulaMixer Sample Mixer, Invitrogen, Carlsbad, CA, USA). The slurry was centrifuged at $10,000 \times g$ for $10 \mathrm{~min}$ at $4{ }^{\circ} \mathrm{C}$, and the supernatant was filtered through a $0.45 \mu \mathrm{m}$ syringe filter (Sartorius AG, Goettingen, Germany). 
DNA extraction and purification for real time PCR analysis of samples was performed as previously described [11]. The DNA obtained from the Wizard DNA Clean-Up System kit (Promega, Madison, WI, USA) was eluted in $50 \mu \mathrm{L}$ of sterile deionised water, and DNA concentration was measured with a NanoDrop ND-1000 spectrophotometer (NanoDrop Technologies Inc., Montchanin, Denmark).

A negative control, without sample, was included in every protein or DNA extraction. All protein and DNA extracts were stored at $-20^{\circ} \mathrm{C}$.

\subsection{Sequence Analysis}

DNA from single colonies of the pistachio-recognizing clones was amplified using My Taq Mix $2 \times$ (Bioline Reagents Limited, London, UK) and primers CDR1-2 Fw (5'-ACGTCAGAAGACATCA GGTGCAGCTGTTGGAGTC-3') and CDR3 Rev (5'-TCAGTTGAAGACCTCGAATTCAGATCCTCTTC TGAGATG-3') [18]. The polymerase chain reaction (PCR) program used was $95^{\circ} \mathrm{C}$ for $2 \mathrm{~min}$, then, $95{ }^{\circ} \mathrm{C}$ for $15 \mathrm{~s}, 60^{\circ} \mathrm{C}$ for $15 \mathrm{~s}, 72{ }^{\circ} \mathrm{C}$ for $10 \mathrm{~s}$ for 30 cycles, and a final extension at $72{ }^{\circ} \mathrm{C}$ for $7 \mathrm{~min}$. PCR products (360-390 bp) were examined by electrophoresis on $1.5 \%$ agarose gel.

To confirm the suitable sequence of the selected clones with a complete $\mathrm{VH}$ fragment, the phagemid DNA was extracted by High Pure Plasmid Isolation kit (F. Hoffmann-La Roche Ltd., Basel, Switzerland) and sequenced with primers M13 Rev (5'-CAGGAAACAGCTATGACC-3') and pR2seq (5'-CCCTCATAGTTAGCGTAACGA-3') at Unidad de Genómica (Universidad Complutense de Madrid) with a multi-capillary sequencer "ABI Prism 3730" (Applied Biosystems, Waltham, Massachusetts, USA).

Nucleotide sequences were compared using European Molecular Biology Open Software Suite (Emboss software), and then analysed with IMGT/V-QUEST (sequence alignment software for IG and TR) to determine framework and complementary determining regions (CDR) of the VH. Amino acid sequences were deduced from the nucleotide sequences by SnapGene software (Insightful Science; available at snapgene.com).

\subsection{Biopanning Procedure}

The phage display $\mathrm{dAb}$ library was prepared as recommended by the manufacturer [17]. Following amplification of the library and precipitation of the phage particles, the pellet was resuspended in $1 \mathrm{~mL}$ of PBS and centrifuged at $11,600 \times g$ to remove any bacterial debris. The phages were titrered and kept at $4{ }^{\circ} \mathrm{C}$ for short-term storage (one week) or at $-80^{\circ} \mathrm{C}$ in $15 \%$ glycerol for long-term storage.

Different biopanning strategies (S1-S4) were carried out to obtain pistachio specific clones (Table 2). In all the strategies, polystyrene paddles were used as solid phase for the first round of biopanning and magnetic beads for the second round to avoid the isolation of nonspecific binders that would produce false-positive results. For the first round of selection, polystyrene Nunc paddles (Thermo Fisher Scientific, Waltham, MA, USA) with a surface area of $5.2 \mathrm{~cm}^{2}$ were coated with $1 \mathrm{~mL}$ of $100 \mu \mathrm{g} \mathrm{mL}-1$ pistachio extract (positive screening) or peanut or cashew nut extract (negative screening) in PBS and incubated overnight at $4{ }^{\circ} \mathrm{C}$. Then, paddles were washed three times with PBS and blocked with MPBS at $37^{\circ} \mathrm{C}$ for $1 \mathrm{~h}$. For the second round of selection, Dynabeads M-280 Tosylactivated (Thermo Fisher Scientific) were used to bind $100 \mu \mathrm{g}$ of the target proteins following the manufacturer's instructions.

The biopanning processes were performed as described in Madrid et al. [19], but using roasted pistachio, cashew, and peanut whole or defatted extracts, as shown in Table 2. 
Table 2. Different biopanning strategies used, and number of specific pistachio-binding clones obtained from each strategy.

\begin{tabular}{|c|c|c|c|c|c|c|c|c|c|}
\hline \multirow{2}{*}{ Strategies } & \multirow{2}{*}{$\begin{array}{c}\text { Defatted } \\
\text { Extracts }\end{array}$} & \multirow{2}{*}{ Selection $^{a}$} & \multicolumn{3}{|c|}{ Round 1} & \multicolumn{3}{|c|}{ Round 2} & \multirow{2}{*}{$\begin{array}{l}\text { Clones } \\
\text { Obtained }\end{array}$} \\
\hline & & & Peanut & Cashew & Pistachio & Peanut & Cashew & Pistachio & \\
\hline S1 & NO & $\begin{array}{l}- \\
+ \\
\end{array}$ & $\bullet$ & & • & $\bullet$ & & • & 2 \\
\hline S2 & NO & $\begin{array}{l}- \\
+\end{array}$ & $\bullet$ & & • & & $\bullet$ & • & 1 \\
\hline S3 & YES & $\begin{array}{l}+ \\
+ \\
\end{array}$ & $\bullet$ & & • & $\bullet$ & & • & 13 \\
\hline S4 & YES & $\begin{array}{l}- \\
+\end{array}$ & • & & • & & $\bullet$ & • & 4 \\
\hline
\end{tabular}

${ }^{a}$ For each strategy and round of biopanning, a negative panning was first performed with the extract indicated by $(-)$ to reduce non-specific binders. Then, the remaining phage-dAbs were used for selection of pistachio-specific phage-dAbs against the pistachio extract (+).

For the selection of pistachio-specific phage- $\mathrm{dAb}$, two rounds of selection were carried out in each strategy. In the first round, approximately $5 \times 10^{12}$ amplified phages from the dAb library were diluted in $1 \mathrm{~mL}$ of MPBS and added to the appropriate polystyrene paddles for a first negative selection. The mixture was incubated at $25^{\circ} \mathrm{C}$ for $1 \mathrm{~h}$ to capture the phage dAbs that bind cashew or peanut, depending on the strategy. Then, the mixture containing the uncaptured phage-dAbs was added to the paddle coated with pistachio and incubated at $25^{\circ} \mathrm{C}$ for $1 \mathrm{~h}$ with rotation and for another hour without rotation. Unbound phages were then removed by washing 10 times with PBS, and phages specifically bound to pistachio proteins were eluted by adding $1 \mathrm{~mL}$ of trypsin solution $\left(1 \mathrm{~g} \mathrm{~L}^{-1}\right.$ trypsin in PBS) for $1 \mathrm{~h}$ at room temperature with rotation. Ten microliters of eluted phage were used for titration, and $500 \mu \mathrm{L}$ was used to infect $30 \mathrm{~mL}$ of E. coli TG1 culture at an $\mathrm{OD}_{600}$ of 0.5 , and the flask was incubated for $1 \mathrm{~h}$ at $37^{\circ} \mathrm{C}$ in a water bath. Infected cells $(1 \mathrm{~mL})$ were spread on six TYE agar plates containing $100 \mu \mathrm{g} \mathrm{mL} \mathrm{m}^{-1}$ ampicillin and $4 \%(w / v)$ glucose and grown overnight at $37^{\circ} \mathrm{C}$. Following overnight incubation, E. coli colonies were scraped into $2 \mathrm{~mL}$ of $2 \times \mathrm{TY}$ containing $15 \%$ glycerol and stored at $-80^{\circ} \mathrm{C}$ (labelled as first round stock). To amplify the phages for the second round of selection, $1 \mathrm{~mL}$ of recovered bacteria from the first panning (or until $\mathrm{OD}_{600}$ of 0.1 ) were inoculated into $500 \mathrm{~mL}$ of $2 \times \mathrm{TY}$ containing $100 \mu \mathrm{g} \mathrm{mL} \mathrm{m}^{-1}$ ampicillin and $4 \%(w / v)$ glucose and incubated at $37^{\circ} \mathrm{C}$ until reaching an $\mathrm{OD}_{600}$ of 0.5 . Then, infection with helper phage and precipitation was performed as described in Lee et al. [17]. A second round of selection was performed like the first one but employing $5 \mathrm{mg}$ of Dynabeads instead of polystyrene paddles and increasing the number of washes to 20.

To select pistachio-binding clones, 95 individual colonies from the titration plates of the second round of selection were randomly picked and inoculated in separate wells of Nunc cell culture microplates (Thermo Fisher Scientific) containing $200 \mu \mathrm{L} 2 \times \mathrm{TY}$ with $100 \mu \mathrm{g} \mathrm{mL} \mathrm{L}^{-1}$ ampicillin and $4 \%$ $(w / v)$ glucose. Following infection with the helper phage, monoclonal phage-dAbs from the culture supernatant were screened for pistachio binding.

\subsection{Indirect Phage-dAb Enzyme-Linked Immunosorbent Assay (ELISA)}

Flat-bottom polystyrene microtiter plates (F96 MaxiSorp Nunc immunoplates (Thermo Fisher Scientific) were coated with the appropriate dilutions of the protein extracts assayed (pistachio, heterologous species, experimental mixtures, or commercial products) diluted 1:100 in PBS and incubated at $37^{\circ} \mathrm{C}$ for $1 \mathrm{~h}$. Then, the plates were washed five times and blocked with $200 \mu \mathrm{L}$ of MPBS per well for $1 \mathrm{~h}$ at $37^{\circ} \mathrm{C}$. After the plates were washed five times, culture supernatant $(25 \mu \mathrm{L})$ in $100 \mu \mathrm{L}$ of PBS with $3 \%(w / v)$ BSA or $100 \mu \mathrm{L}$ of MPBS containing $2 \mu \mathrm{L}$ of precipitated phage was added to each well, and the plates were incubated for $1 \mathrm{~h}$ at room temperature with shaking. After washing 10 times, plates were incubated at room temperature for $1 \mathrm{~h}$ with $100 \mu \mathrm{L}$ of HRP/anti-M13 monoclonal mouse antibody (GE Healthcare UK Ltd., Amersham, UK) diluted 1:5000 in MPBS. Following another washing step, the reaction was developed with tetramethylbenzidine 
substrate solution $(100 \mu \mathrm{L})$ for $12 \mathrm{~min}$ in the dark and stopped with $50 \mu \mathrm{L} 1 \mathrm{M}$ sulphuric acid. $\mathrm{OD}_{450}$ was measured with a spectrophotometer (FLUOstar Optima, BMG Labtech, Ortenberg, Germany). All washing steps were performed with PBS. All experiments were performed in triplicate. The experimental mixtures containing $5 \times 10^{3}, 10^{4}$, and $10^{5} \mathrm{mg} \mathrm{kg}^{-1}$ pistachio, and also negative control wells (for antigen, phage-dAb and secondary antibody), were analysed along with the food samples (heterologous species and commercial samples) as references and controls.

The concentration-response curve obtained by plotting the absorbance values vs. the log of pistachio protein concentration was fitted to the four-parameter logistic equation using Origin 8.0 software (OriginLab Corp., Northampton, MA, USA).

The limit of detection (LOD) was calculated as the concentration of the target protein that presents an absorbance value higher than the average of the eight non-target tree nuts plus three times its standard deviation (SD).

\subsection{Protein Fractionation of the Pistachio Extract by Size-Exclusion Chromatography}

Size-exclusion chromatography separation was carried out in a fast protein liquid chromatography system (ÄKTA purifier FPLC system) (GE Healthcare UK Ltd., Amersham, UK). One hundred microliter of defatted and filtered pistachio protein extract was injected into a HiPrep 16/60 Sephacryl S-200 HR column (GE Healthcare UK Ltd., Amersham, UK) previously equilibrated with PBS. The flow rate was maintained at $0.5 \mathrm{~mL} \mathrm{~min}{ }^{-1}$. Eluted fractions were collected in $1.5 \mathrm{~mL}$ glass vials and stored at $-20^{\circ} \mathrm{C}$ until further use.

\subsection{SDS-PAGE and Western Blotting Analysis}

Duplicate sodium dodecyl sulphate polyacrylamide gel electrophoresis (SDS-PAGE) of the size exclusion chromatography fractions $(5 \mu \mathrm{g} / \mathrm{lane})$ and pistachio extracts $(10 \mu \mathrm{g})$ were performed using precast gels (4-20\% TDX, Bio-Rad, Hercules, CA, USA) in a Mini-Protean Tetra Cell (Bio-Rad) at $120 \mathrm{~V}$ for $45 \mathrm{~min}$. Each sample was mixed with $10 \mu \mathrm{L}$ of sample buffer and heated at $95{ }^{\circ} \mathrm{C}$ for 5 min before addition to the wells. Following electrophoresis, one of the gels was stained with Blue safe (NZytech, Lisbon, Portugal), and protein bands in the other gel were transferred into a methanol-activated polyvinylidene difluoride (PVDF) membrane (Immuno-Blot PVDF membranes; Bio-Rad) at $240 \mathrm{~mA}$ for $2 \mathrm{~h}$ using a Mini Trans-Blot Cell (Bio-Rad). The membrane was then blocked with $3 \%$ BSA in PBS for $1 \mathrm{~h}$ at $25^{\circ} \mathrm{C}$, washed three times with PBS, and incubated overnight at $4{ }^{\circ} \mathrm{C}$ with pistachio specific phage-dAb (750 $\mu \mathrm{L}$ of PVF4 clone culture supernatant diluted with $2.25 \mathrm{~mL}$ of $1 \%$ of BSA in PBS). After washing five times with PBS, the membrane was incubated for $1 \mathrm{~h}$ at $37^{\circ} \mathrm{C}$ with HRP/anti-M13 mouse monoclonal antibody (GE Healthcare UK Ltd., Amersham, UK) diluted 1:5000 in 1\% BSA-PBS, washed three times with PBST and revealed with the chemiluminescent substrate Clarity Western ECL (Bio-Rad). The Western blotting membranes were scanned using a ChemiDoc XRS system (Bio-Rad) to visualise bands.

\subsection{Protein Identification}

Bands of interest from the Blue Safe stained SDS-PAGE gel were cut out with a sterile scalpel and immersed in 5\% acetic acid solution. Proteins were in gel reduced, alkylated, and digested with trypsin according to Sechi and Chait [20]. Analysis of peptides from protein digestion was performed using the 4800 Plus MALDI-TOF/TOF (matrix-assisted laser desorption/ionization tandem mass spectrometry) Analyzer mass spectrometer (Applied Biosystems, MDS Sciex, Toronto, ON, Canada), at the Unidad de Proteómica of Universidad Complutense de Madrid (Spain). Peptide mass fingerprint and some peptide fragmentation spectra were combined searched in the MASCOT v2.3 search engine (http://www.matrixscience.com) through Global protein Server (Applied Biosystems) against NCBI database (17,919,084 sequences; 6,150,218,869 residues) without taxonomy restriction and search parameters: carbamidomethylcysteine as fixed modification and oxidised methionine as variable modification; peptide mass tolerance $80 \mathrm{ppm}$; one missed trypsin cleavage site allowed and MS/MS 
fragments tolerance 0.3 Da. In all protein identification, the probability scores were greater than the score fixed by Mascot as significant with a $p$-value minor than 0.05 .

\section{Results and Discussion}

\subsection{Screening of the Domain Antibody (dAb) Library in Search for Pistachio-Specific Clones}

Domain antibody $(\mathrm{dAb})$ libraries are novel tools in the phage display technology for the obtention of recombinant antibody fragments. Compared with Fab or scFv libraries [21], randomization in dAb constructions can be introduced at a much higher percentage of CDR positions without exceeding practical library size, being simpler and more efficient.

Pistachio and cashew belong to the Anacardiaceae family, and due to its phylogenetic proximity, it is difficult to obtain pistachio-specific antibodies that do not have a cross reaction with cashew [2]. A commercial $\mathrm{dAb}$ library has been searched in a phage display format to obtain specific clones for detection of pistachio in processed foods. Several biopanning strategies (S1-S4) involving two rounds of selection were carried out using protein extracts from whole (S1 and S2) or defatted (S3 and S4) pistachio, cashew, and peanut (Table 2).

The input number of phage particles was always around $5 \times 10^{12} \mathrm{pfu} \mathrm{mL}^{-1}$ and, as expected, the phage particles recovered at the end of the first round were around $10^{5}-10^{7} \mathrm{pfu} \mathrm{mL} \mathrm{m}^{-1}$, increasing up to $10^{7}-10^{9}$ in subsequent rounds of selection [17]. That was the case for all biopanning strategies (Figure 1), and it could be indicative of an increase in the selection of binders to pistachio.

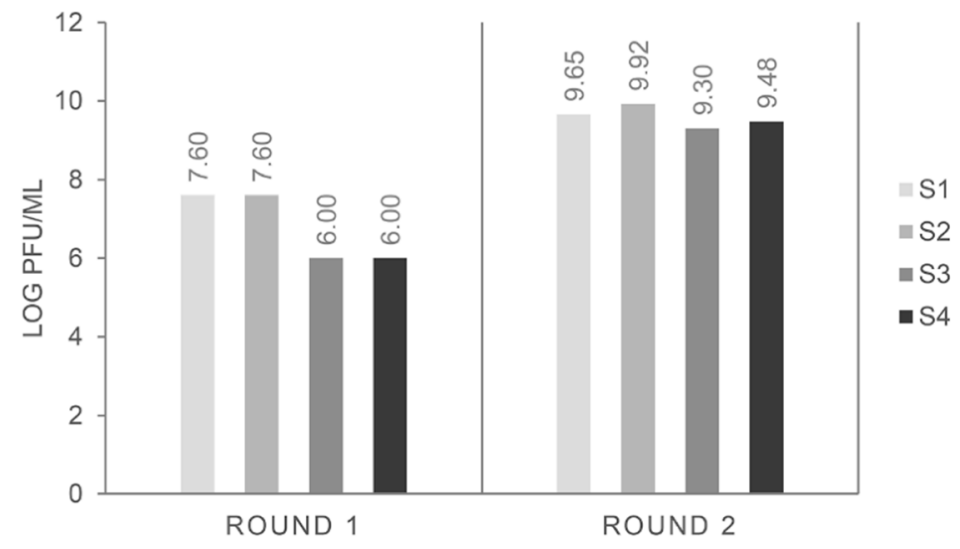

Figure 1. Phage titers obtained after each round of affinity selection against pistachio extract, following different biopanning strategies (S1-S4).

To confirm this hypothesis, a polyclonal phage ELISA against pistachio, cashew, and peanut was performed with phage pools collected from all the rounds of selection, using BSA and $\beta$-galactosidase as negative controls (Figure 2).

The results showed an increase in absorbance values for pistachio proteins after the second rounds, with important differences between strategies. When whole protein extracts were used as a target, pistachio binding increased only slightly in S1, and it did not increase further in S2. On the contrary, using defatted extracts as target allowed a clear enrichment in pistachio binding phage-dAb, with higher values registered in S3 (subtraction of peanut-binding phages in rounds 1 and 2 before selection of pistachio-binding phages) than in $\mathrm{S} 4$ (subtraction of peanut-binding phages in round 1 and cashew-binding phages in round 2). This result could mean that a negative selection against cashew produced recovery of a lower number of pistachio-binding phages but more specific to the pistachio target. Very low cross-reactivity was found to wells coated with BSA, $\beta$-galactosidase, cashew, and peanut. Thus, according to these results, the use of defatted extracts increased the efficiency of the biopanning process, so that the phage population that specifically recognised pistachio was highly enriched in the second round of panning, avoiding the need for additional rounds of selection. 


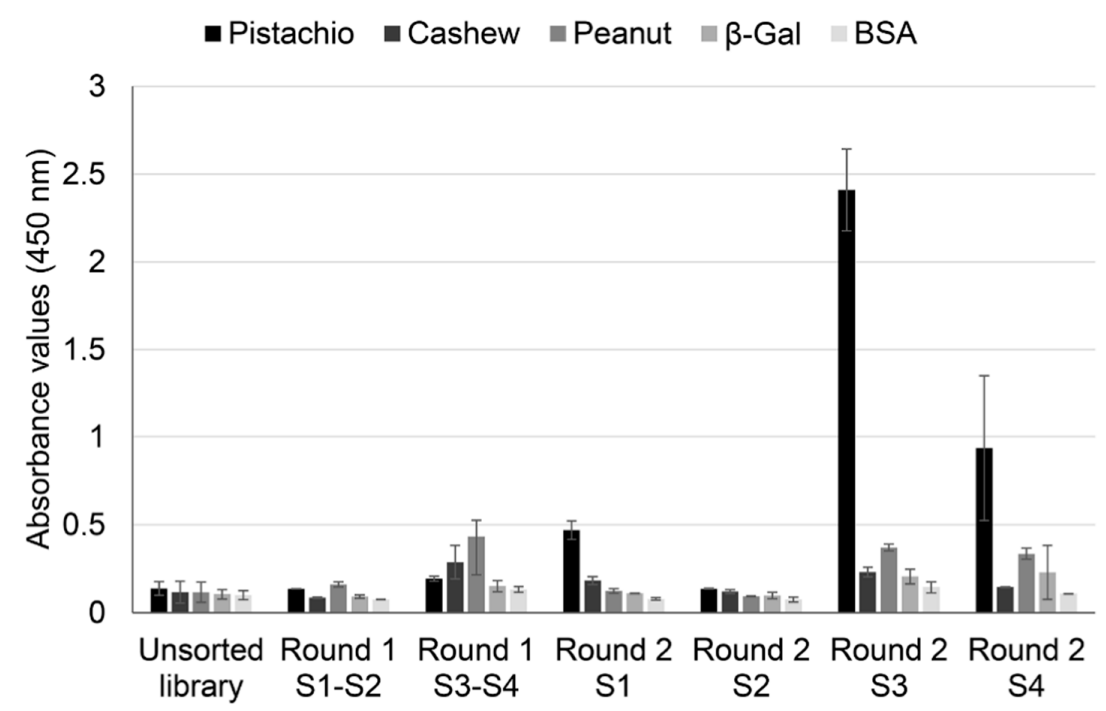

Figure 2. Indirect phage-dAb ELISA results obtained with polyclonal phages rescued at each round of selection from strategies S1-S4 against pistachio. Precipitated phages from each round of selection were analysed against pistachio, cashew and peanut extracts and negative controls (beta-galactosidase and BSA). Absorbance values are the mean of three independent experiments with duplicates. Error bars show the standard deviation for each set of data.

\subsection{Screening of Individual Phage-dAb Clones by Monoclonal Phage ELISA}

Monoclonal phage ELISA was performed to isolate and identify clones producing $\mathrm{dAb}$ that recognised pistachio proteins. Ninety-five $E$. coli TG1 colonies from the titration plates of the second rounds of panning of the different strategies were picked, and phage-dAbs produced in the culture supernatant were analysed. The clones were considered positive when binding to pistachio extract was at least five times higher than binding to the peanut or cashew extracts used as negative controls $\left(\mathrm{A}_{450}\right.$ against pistachio $>5 \times \mathrm{A}_{450}$ against negative control).

When the negative selection was made with peanut (S1), two clones recognizing pistachio were obtained (PVD5 and PVF10), but they also cross-reacted with cashew (Table 2). It is possible that negative subtraction with peanut eliminated clones recognizing other tree nuts, but the remaining pistachio-binding clones also recognised the phylogenetically close cashew. In strategy S2, the negative selection was performed with peanut in round 1 and with cashew in round 2 . This strategy yielded just one positive clone that exclusively recognised pistachio (PVG3). Finally, this clone was discarded because its nucleotide sequence revealed that it did not codify for a complete $\mathrm{dAb}$, generating a truncated antibody without the signal factor, the FR1, and part of the CDR1.

Pistachios are characterised by a high fat content (between $40.6-53.5 \% \mathrm{~g}$ per $100 \mathrm{~g}$ ) with a heart-healthy fatty acid profile [22,23]. They are also rich in polyphenols (around $600 \mathrm{mg}$ per $100 \mathrm{~g}$ ) [24]. Polyphenols are known to form complexes with proteins leading to changes in the structural, functional and nutritional properties of both compounds [25]. Considering that the high fat content of pistachio and other tree nuts could be hindering obtention of pistachio specific $\mathrm{dAb}$, the same biopanning strategies used with whole extracts (S1 and S2) were performed but using defatted extracts of pistachio, peanut and cashew. In the strategy S3 a total of 13 pistachio binding clones were obtained out of the 95 clones analysed (13.7\%) from the second round (Table 2). Three of them showed cross reaction with the cashew extract (PVA7, PVA8 and PVD8), and the remaining clones bound only pistachio (PVB4, PVB9, PVC11, PVC12, PVD6, PVE12, PVF6, PVF9, PVG8, and PVH7). In the S4 strategy, there were four pistachio-binding clones out of 95 clones analysed from the second round $(4.2 \%)$. Three of them were considered specific to pistachio (PVA1, PVA12, and PVF4), and only one cross-reacted with cashew (PVB12). Following initial screening, eight clones from the second rounds of S3 and S4 were selected for further analysis in a monoclonal ELISA with phage-dAb to assess 
specificity against ten allergenic nut species (Figure 3). The eight selected clones bound pistachio with $\mathrm{ABS}_{450}$ values higher than 1.5, without cross-reactivity to the rest of the nuts. Only the clone PVA8 (S3) cross-reacted to the cashew extract, and it was then discarded.

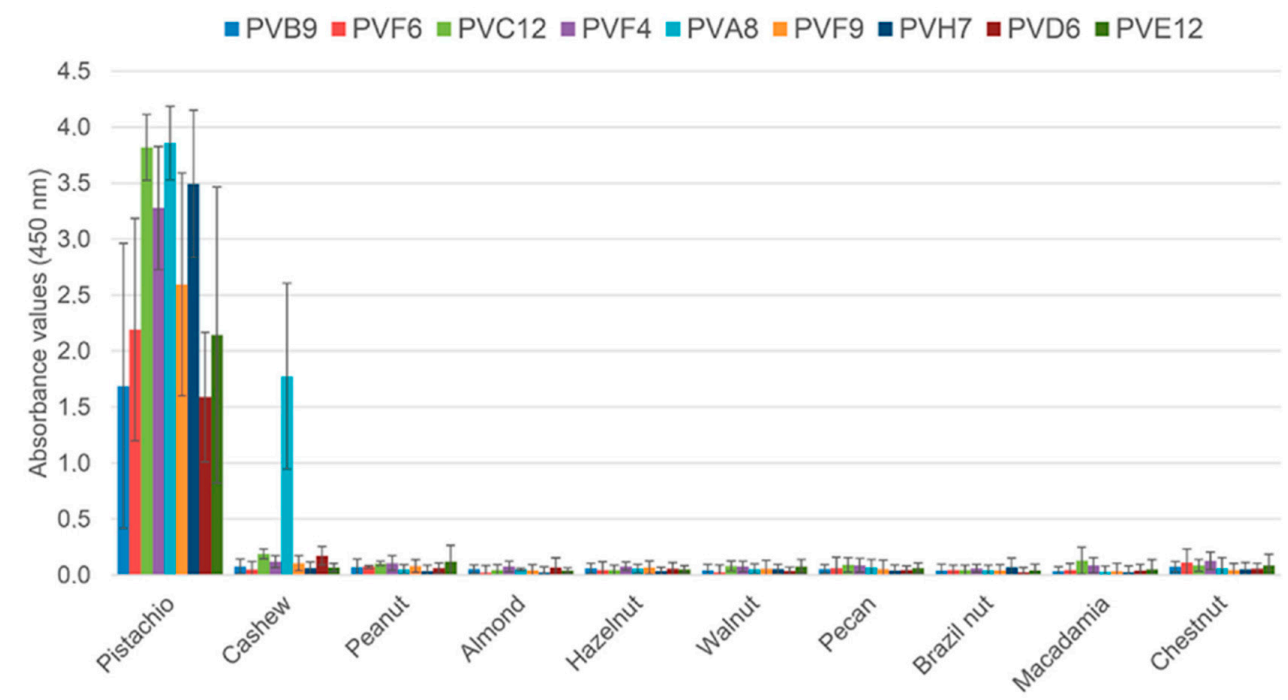

Figure 3. Indirect phage-dAb ELISA results obtained with monoclonal phages selected from the second round of biopanning against a set of tree nuts. Absorbance values are the mean of four independent experiments with duplicates. Error bars show the standard deviation for each set of data.

These results demonstrated that negative biopanning with a closely related but non-target protein (cashew extract) excluded a part of the pistachio reactive phages, but still allowed selection of the most specific phage-dAb. Moreover, the use of defatted extracts was necessary to obtain pistachio-specific clones. The defatting protocol (Section 2.1) was performed with acetone, which is a good method to eliminate fatty acids and also improves the extraction of polyphenols [24,26]. Therefore, the extracts used in strategies S3 and S4 are characterised by a high protein content without elements such as fatty acids and phenols that interact or prevent recognition of the protein epitopes by $\mathrm{dAb}$, thus improving the efficiency of the selection of phage antibodies.

\subsection{Sequence Analysis}

DNA from the eight pistachio-specific clones selected, and one of the clones cross-reacting with cashew, was amplified by PCR with primers CDR1-2 and CDR3 to estimate the proportion of clones containing the complete VH insert (approximately 360-390 bp); all of them produced PCR fragments of the expected size (not shown). The inserts of the purified plasmids were then sequenced, and the sequences were uploaded to GenBank with the following accession numbers: PVA8-dAb (MN862009), PVB9-dAb (MN631054), PVD6-dAb (MN862010), PVE12-dAb (MN862011), PVF4-dAb (MN612110), PVF6-dAb (MN631055), PVF9-dAb (MN862012), and PVH7-dAb (MN862013). When compared to the NCBI database, the selected positive clones were confirmed to be Homo sapiens partial IGHV3-23 gene for immunoglobulin heavy chain variable region. Finally, DNA sequence analysis of the nine clones and their deduced amino acid sequences (Figure 4) demonstrated that they were all different except dAbs PVF4, obtained with strategy S4, and PVC12, obtained with strategy S3, that had the same nucleotide sequence. The clone PVF4 was then selected because of its higher culture stability and phage-dAb production. 


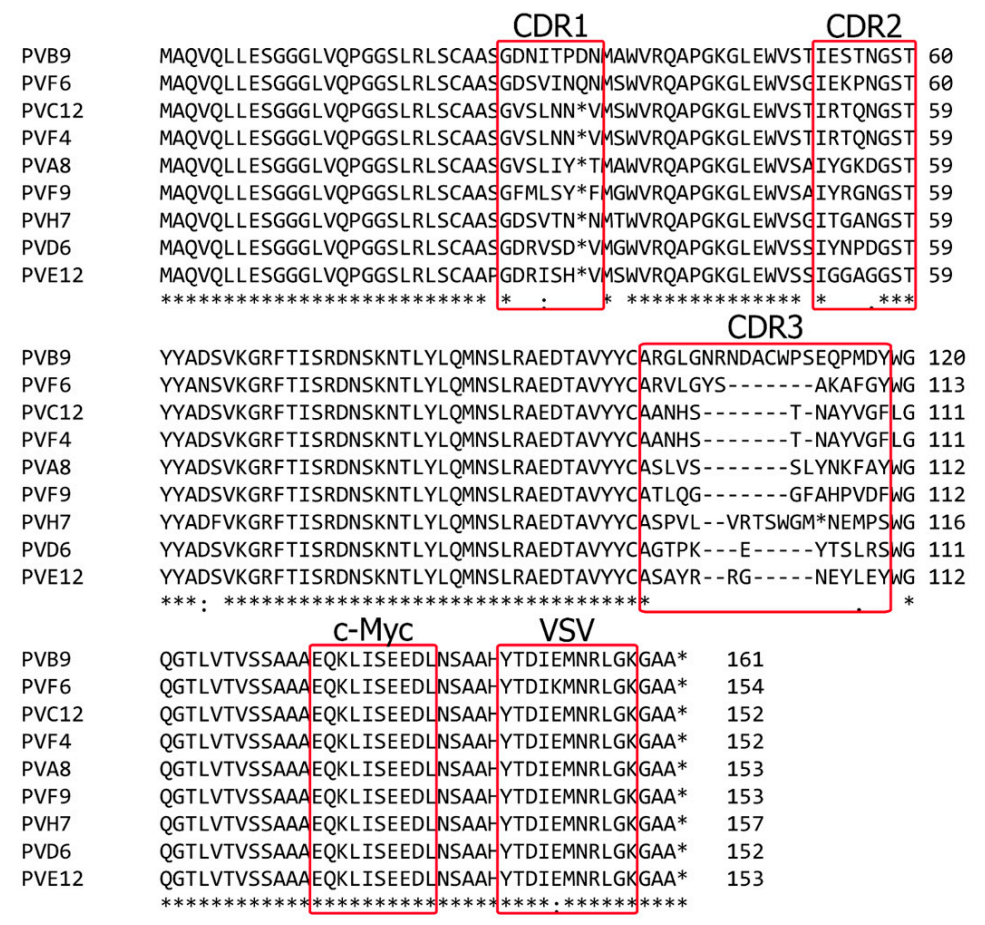

Figure 4. Amino acid sequences of the pistachio binding dAbs deduced from the nucleotide sequences by SnapGene tool. Positions of the complementarity determining regions of the variable domains (CDR 1-3) and the c-Myc and VSV tags are indicated as determined by IMGT/V-QUEST tool.

Deduced amino acid sequences of the pistachio-binding clones showing the CDRs and immunoglobulin framework regions (FRs) demonstrated no insertions or deletions in CDR1 and CDR2 in any of the clones. As expected, CDR3 was the most variable in sequence and length among the selected clones, with lengths from 12 to 20 residues. Moreover, a stop codon was present in the CDR1 of six clones, and in CDR3 or one clone, due to an amber mutation (Figure 4). This is frequent in phage displayed antibodies because of randomization of CDR sequences and propagation of phagemids in the amber suppressor TG1 E. coli strain [27]. Amber stop codons are interpreted as Gln residues in suppressor strains like TG1, so that these $\mathrm{dAb}$ clones can be used in a phage display format, but require site directed mutagenesis to be produced as soluble dAbs in a non-suppressor strain.

The target-binding site of human antibodies is usually composed by the variable domains of the heavy and light chains ( $\mathrm{VH}$ and $\mathrm{VL}$ ), that are non-covalently associated, and together contribute for proper target binding. However, there are naturally occurring and genetically engineered single chain antibodies that maintain their ability to recognise antigens with high affinity and specificity $[15,17]$. That is the case of the human-domain antibody library $(\mathrm{dAb})$ used in this work, which consisted of antibody fragments based exclusively on a single $\mathrm{VH}$ domain [17]. Advantageous features of dAbs include their small size $(15 \mathrm{kDa})$, high solubility and stability, and excellent tissue penetration in vivo. Domain antibodies can be genetically linked to peptide tags as c-Myc or His tags to facilitate their purification when produced as soluble antibody fragments.

\subsection{Identification of Pistachio Proteins Recognised by the PVF4 Phage-dAb}

To identify the protein fractions recognised by the PVF4 phage-dAb, a chromatographic separation of the defatted pistachio extract was performed by FPLC, followed by an indirect phage-dAb ELISA and a Western blot with FPLC fractions.

Size-exclusion chromatography with FPLC system of defatted pistachio protein extract was resolved in a protein profile with two major peaks and three minor peaks at $280 \mathrm{~nm}$ (Figure 5A). One hundred microlitres of representative protein fractions obtained from size-exclusion chromatography were analysed in an indirect-phage ELISA using PVF4 phage-dAb (Figure 5B). 


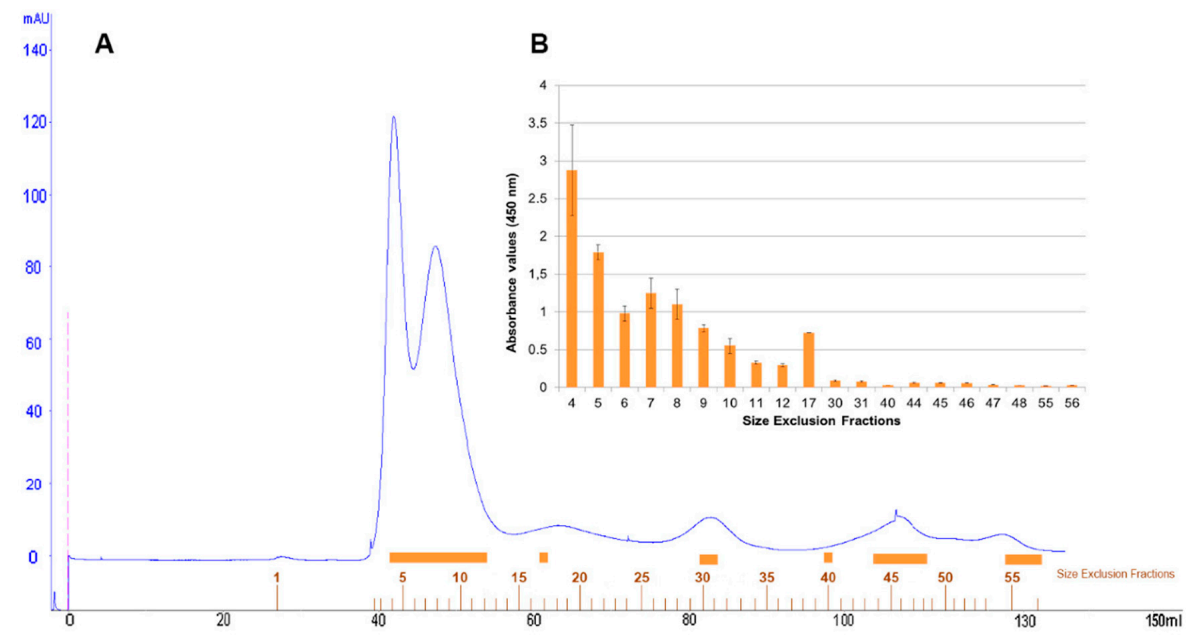

Figure 5. Elution profile of pistachio proteins obtained from preparative FPLC size exclusion column (A) showing absorbance values at $280 \mathrm{~nm}$. (B) Indirect phage-dAb ELISA with some fractions obtained from FPLC (indicated by an orange bar). Absorbance values are the mean of duplicates. Error bars show the standard deviation for each set of data.

Fractions 4-17, belonging to the two major and first minor peaks, were detected by the PVF4 phage- $\mathrm{dAb}$. In order to identify the specific proteins recognised by PVF4 phage- $\mathrm{dAb}$, an SDS-PAGE of the pistachio extract and selected fractions was performed under reducing conditions. The most prominent electrophoretic bands had molecular weights ranging from $\sim 20 \mathrm{kDa}$ to $\sim 35 \mathrm{kDa}$ (Figure $6 \mathrm{~A}$ ).

A

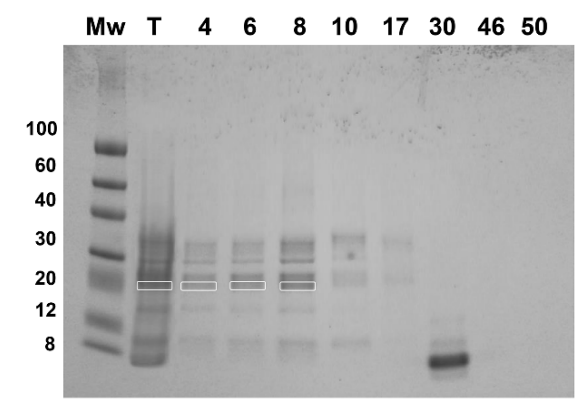

B

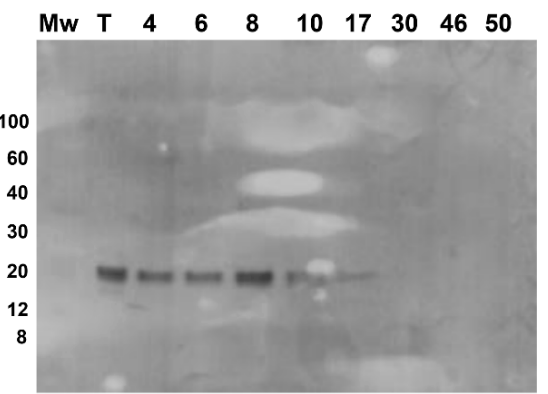

Figure 6. Sodium dodecyl sulphate polyacrylamide gel electrophoresis (SDS-PAGE) in reducing conditions of different fractions obtained in size exclusion chromatography (A) and immunoblot with PVF4 phage-dAb (B) of $10 \mu \mathrm{g}$ of pistachio extract (T) and $10 \mu \mathrm{L}$ of each fraction sample. Mw of the protein marker bands (ColorBurst ${ }^{\mathrm{TM}}$ Electrophoresis Protein Marker, Merck KGaA, Darmstadt, Germany) is indicated. Highlighted bands were excised and analysed by matrix-assisted laser desorption/ionization tandem mass spectrometry (MALDI-TOF/TOF). Phage-dAb in the immunoblot was detected with anti-M13 monoclonal mouse antibody conjugated with Horseradish peroxidase (HRP).

The electrophoretic and Western blot patterns of total pistachio extract and fractions 4-17 were similar to those reported by Liu et al. [10] under reducing conditions with a murine monoclonal antibody against pistachio. A unique band of $\sim 22 \mathrm{kDa}$ was detected in the Western blot by the PVF4 phage-dAb (Figure 6B). According to Liu et al. [10], the target antigen is likely to be the basic subunit of the pistachio 11S globulin (allergen Pis $\mathrm{v} 2$ ) that belongs to the cupin superfamily of proteins, and has been identified as a major pistachio allergen [4]. To verify the hypothesis, the bands from total extract and fractions 4,6 , and 8 recognised by the PVF4 phage-dAb were excised and analysed by matrix-assisted laser desorption/ionization tandem mass spectrometry (MALDI-TOF/TOF). As shown in Table S1, the peptides obtained from all the bands were identified in the amino acid sequence of the 
$11 \mathrm{~S}$ globulin (Pistacia vera) (accession number: ABU42022). The coverage of the $11 \mathrm{~S}$ sequence obtained was $45 \%$ in the case of lane T, $22 \%$ for lane $4,30 \%$ for lane 6 , and $25 \%$ for lane 8 (Table S1).

Here, $11 \mathrm{~S}$ globulins are defined as bicupins owing to the presence of two cupin domains, each presenting a beta-barrel motif. They are non-glycosylated multimeric structures (hexamers or mixture of trimers) synthesised as a single polypeptide, which is post-translationally cleaved into an acidic ( $30-40 \mathrm{kDa})$ and a basic $(22-27 \mathrm{kDa})$ polypeptides linked by a disulphide bond [4,5,10]. It should be noted that most of the peptides obtained from lanes 4,6 , and 8 , aligned to the C-terminal region of the protein sequence, while peptides in the band from the total extract aligned throughout the whole sequence (Figure 7).

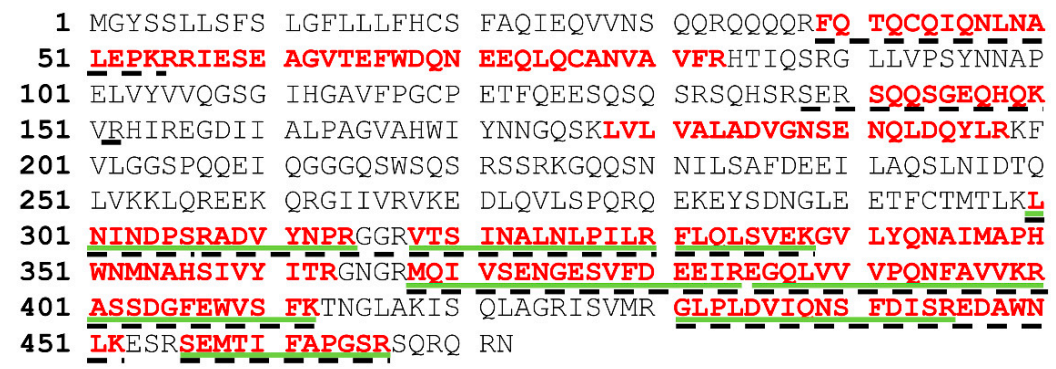

Figure 7. Amino acid sequence of the 11 S globulin (Pistacia vera) (accession number: ABU42022). Positions of peptides identified by matrix-assisted laser desorption/ionization tandem mass spectrometry (MALDI-TOF/TOF) from lane ' $\mathrm{T}$ ' in the Western blot are in red bold font. Positions of the peptides identified from the lane ' 4 ' are underlined with green solid lines. Positions of the peptides identified from lanes ' 6 ' and ' 8 ' are discontinuous underlined.

The 3D structure of the pistachio 11S globulin (ABU42022) identified as target of the PVF4 phage-dAb by MALDI-TOF/TOF, was predicted by homology modelling, using the SWISS-MODEL server (Figure 8) https://swissmodel.expasy.org/ [28]. The model was built through comparison to the closely related sequence and structure of the $11 \mathrm{~S}$ globulin seed storage protein from Amaranthus hypochondriacus L., 3qac.1.A, which served as template. Most of the peptides identified by MALDI-TOF/TOF, seem to belong to the basic protein subunit (Cupine-1) of the 11S globulin [2,4]. This result agrees with Liu et al., [10], indicating that pistachio 11S globulin basic subunit is a good antigen for producing antibodies targeting human allergy relevant epitopes.

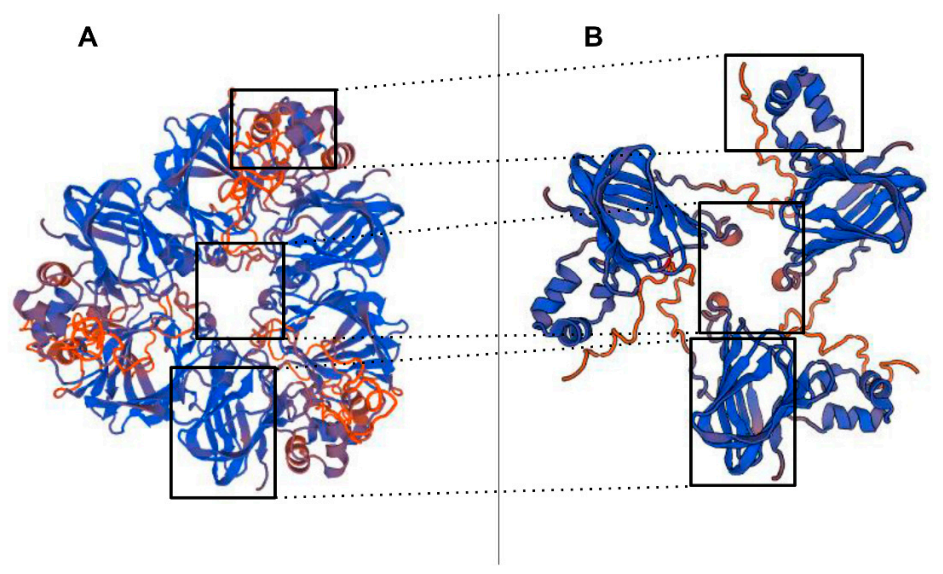

Figure 8. The $11 S$ globulins are hexameric proteins with subunits comprising an acidic polypeptide 30-40 kDa in size that is disulphide-linked to a $20 \mathrm{kDa}$ basic polypeptide. (A) SWISS-MODEL of a homo-trimer of pistachio 11S globulin seed storage protein (ABU42022), (B) SWISS-MODEL of the basic subunit homo-trimer recognised by PVF4-dAb, the rectangles show the possible epitope recognition zones. 


\subsection{Assay Specificity and Detection Limit}

Indirect phage ELISA assay using precipitated phage-dAb antibody from clone PVF4 was able to detect pistachio proteins from all the raw and roasted pistachio kernels of different origins that were analysed (Spain, Iran, and the US). Roasted pistachios were used for the biopanning process in search for pistachio-specific recombinant antibodies because heat treatments may affect the solubility and integrity of the nut proteins and limit their recognition in the ELISA [29].

Experimental pistachio/corn flour mixtures instead of pistachio extract dilutions were prepared and analysed in the indirect phage-dAb ELISA to assess sensitivity because the food matrix may affect assay performance due to the presence of interfering matrix components. It was demonstrated that the assay was able to detect pistachio proteins in a corn flour matrix in a concentration-dependent manner (Figure 9). The four-parameter logistic equation obtained with the experimental data was $y=\mathrm{A}_{2}+\left(\mathrm{A}_{1}-\mathrm{A}_{2}\right) /\left(1+\left(\mathrm{x} / \mathrm{x}_{0}\right) \hat{\mathrm{p}}\right)$; being $\mathrm{A}_{1}=0.1735, \mathrm{~A}_{2}=4.2209, \mathrm{x}_{0}=4.68007, p=15.42781$ and $R^{2}=0.99869$. The limit of detection (LOD) of this indirect phage-dAb ELISA was $3983 \mathrm{mg} \mathrm{kg}^{-1}$. The coefficients of variation were in the range of $2-15 \%$ for mixtures containing pistachio above the LOD. This LOD is higher than the detection limits reported for other immunoassays and commercial kits available to detect pistachio using polyclonal or monoclonal antibodies. The LOD of pistachio nut protein reported for the MonoTrace pistachio ELISA kit (BioFront Technologies, Tallahassee, FL, USA) and AgraQuant ELISA pistachio (Romer Labs, Tulln, Austria) are $0.12-0.13 \mathrm{mg} \mathrm{kg}^{-1}$ in various matrices, while the LOD for several lateral flow devices (LFD) are in the range of $1-10 \mathrm{mg} \mathrm{kg}^{-1}[5,10]$.

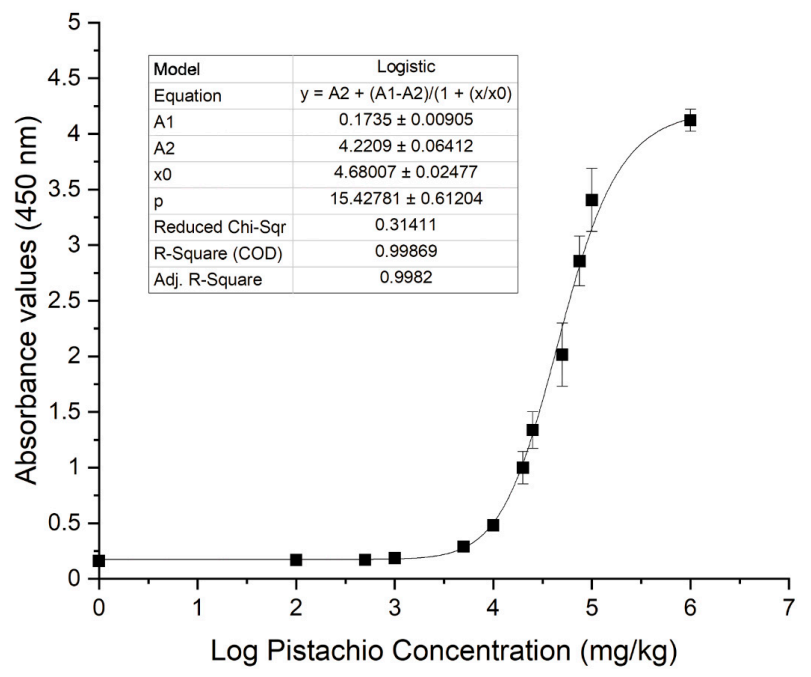

Figure 9. Standard curve of the phage-dAb enzyme-linked immunosorbent assay (ELISA) performed with protein extracts obtained from ground defatted pistachio (匹) in corn flour binary mixtures. The plot shows the average values and the standard deviations corresponding to duplicate experiments performed in three different days.

Cross-reactivity of the assay was calculated as the amount of pistachio estimated by interpolating the absorbance values of the heterologous species in the logistic equation. Cross-reactivity assays using PVF4 phage-dAb showed that none of a wide variety of plant and animal species (Table 1) developed an absorbance signal higher than the LOD of pistachio proteins. Only the egg yolk extract produced a cross-reaction of $4.30 \%$, but not the egg white. Even though this could produce some false positives in products containing egg yolk, most commercial products declaring egg usually contain egg white, which also contains most of the egg allergens [30] but does not cross-react in this assay. However, in contrast to other published immunoassays, that present a high cross-reaction with cashew (approximately 12\% [5], or even higher than 90\% [31]), the PVF4 phage-dAb does not cross-react with cashew. Hence, taken together these results suggest that the PVF4 phage-dAb ELISA is specific but not as sensitive as the previously developed real time PCR technique [11] for pistachio $\left(0.1 \mathrm{mg} \mathrm{kg}^{-1}\right)$, or other published ELISA methods using polyclonal or monoclonal antibodies [32]. 


\subsection{Analysis of Commercial Food Products}

The applicability of the indirect phage ELISA method developed for detection of pistachio proteins in foodstuffs was assessed through analysis of 77 commercial products acquired at different stores of Madrid, including bakery and pastry products, energy bars, chocolates, ice creams, yoghurts, beverages, sauces and prepared dishes. The samples were classified into four groups depending on their content in pistachio and other nuts as declared in their labelling (Table 3).

Among the samples analysed, 34 were labelled as containing pistachio as ingredient, five labelled as 'pistachio traces', 29 declared to contain other tree nuts different than pistachio or tree nut traces, and the remaining nine did not declare to contain any nuts or traces thereof. In order to confirm the results obtained in the phage ELISA, samples were also analysed by the pistachio-specific real-time PCR method previously developed in our laboratory [11].

Table 3. Determination of the presence of pistachio in commercial processed food products using PVF4 phage-dAb ELISA and pistachio-specific real-time polymerase chain reaction (PCR).

\begin{tabular}{|c|c|c|c|c|}
\hline Label Statement & Product & $\begin{array}{l}\text { Number of } \\
\text { Samples }\end{array}$ & $\begin{array}{c}\text { Pistachio Phage-dAb } \\
\text { ELISA }^{a}\end{array}$ & Real Time PCR ${ }^{a}$ \\
\hline \multirow{8}{*}{$\begin{array}{l}\text { Pistachio declared as } \\
\text { ingredient }\end{array}$} & Biscuit & 2 & $-(2)$ & $+(2)$ \\
\hline & Cake & 5 & $+(4) /-(1)$ & $+(5)$ \\
\hline & Chocolate & 3 & $+(1) /-(2)$ & $+(2) /-(1)$ \\
\hline & Cold Meat & 14 & $+(9) /-(5)$ & $+(14)$ \\
\hline & Pistachio Pate & 1 & $-(1)$ & $+(1)$ \\
\hline & Breakfast Cereals & 1 & $-(1)$ & $+(1)$ \\
\hline & Ice-cream & 2 & $+(1) /-(1)$ & $+(2)$ \\
\hline & Snack & 6 & $+(5) /-(1)$ & $+(6)$ \\
\hline \multirow{5}{*}{ Pistachio Traces } & Biscuits & 1 & $-(1)$ & $-(1)$ \\
\hline & Chocolate & 1 & $-(1)$ & $-(1)$ \\
\hline & Cold Meat & 1 & $-(1)$ & $+(1)$ \\
\hline & Stuffed Pasta & 1 & $+(1)$ & $+(1)$ \\
\hline & Sausages & 1 & $+(1)$ & $+(1)$ \\
\hline \multirow{14}{*}{$\begin{array}{l}\text { Contain other tree } \\
\text { nuts or may contain } \\
\text { tree nuts traces }\end{array}$} & Beverage & 1 & $-(1)$ & $-(1)$ \\
\hline & Biscuit & 4 & $-(4)$ & $-(4)$ \\
\hline & Bread & 2 & $-(2)$ & $-(2)$ \\
\hline & Butter & 1 & $-(1)$ & $-(1)$ \\
\hline & Cake & 1 & $-(1)$ & $-(1)$ \\
\hline & Breakfast Cereals & 4 & $-(4)$ & $-(4)$ \\
\hline & Cream & 1 & $-(1)$ & $-(1)$ \\
\hline & Food Bar & 7 & $-(7)$ & $-(7)$ \\
\hline & Ice-Cream & 2 & $-(2)$ & $-(2)$ \\
\hline & Sandwich & 1 & $-(1)$ & $-(1)$ \\
\hline & Sauce & 2 & $-(2)$ & $-(2)$ \\
\hline & Snack & 1 & $-(1)$ & $-(1)$ \\
\hline & Turron & 1 & $-(1)$ & $-(1)$ \\
\hline & Yogurt & 1 & $-(1)$ & $-(1)$ \\
\hline \multirow{7}{*}{$\begin{array}{l}\text { Not declaring to } \\
\text { contain nuts or traces }\end{array}$} & Beverage & 1 & $-(1)$ & $-(1)$ \\
\hline & Biscuit & 2 & $-(2)$ & $-(2)$ \\
\hline & Bread & 2 & $-(2)$ & $-(2)$ \\
\hline & Cake & 1 & $-(1)$ & $-(1)$ \\
\hline & Breakfast Cereals & 1 & $-(1)$ & $-(1)$ \\
\hline & Ice-Cream & 1 & $-(1)$ & $-(1)$ \\
\hline & Snack & 1 & $-(1)$ & $-(1)$ \\
\hline
\end{tabular}

a Commercial food products showing estimated pistachio concentration lower than the limit of detection (LOD) in the phage-dAb ELISA, or $\mathrm{Cp}>30$ (equivalent to $1 \mathrm{mg} \mathrm{kg}^{-1}$ in PCR) were considered negative (-). The number of negative $(-)$ and positive $(+)$ samples detected are indicated in parenthesis.

From 34 commercial products containing pistachio in the list of ingredients, only a chocolate sample tested negative by real-time PCR. Nevertheless, 14 samples tested negative for pistachio by phage-dAb ELISA, including biscuits (2), cake (1), cold meat (5), chocolate (2), pate (1), breakfast cereal (1), ice-cream (1), and snack (1). Negative ELISA results could be explained either because the pistachio concentration in the products is below the LOD or because of a denaturation of the epitope recognised 
by the phage- $\mathrm{dAb}$ due to food processing. In the case of the biscuits, chocolate, and cake samples that tested negative, the pistachio content was not specified in the label, and it could be below the LOD. Some samples that tested negative by ELISA but positive by PCR declared their pistachio content, like the cold meats $(0.2-1 \%)$, pate (35\% boiled pistachio), ice-cream $(1.5 \%)$, and snack ( $5 \%)$, but they are heat treated products, where the processing temperature may have produced the unfolding of the tertiary structure of the proteins and the aggregation of protein chains, avoiding epitope binding by the phage- $\mathrm{dAb}[29,33]$.

Among the five products that included precautionary advisory labelling regarding pistachio, one was positive only by PCR (a cold meat), and two samples tested positive by both methods (a stuffed pasta and a sausage).

In the group of 29 samples with labels indicating that they contain tree nuts other than pistachio or tree nut traces, all samples were negative by the phage-ELISA and real-time PCR methods, verifying a correct food labelling. It should be noted that 10 of the samples declared cashew nuts in the ingredient list and all tested negative in both ELISA and PCR pistachio methods, demonstrating the absence of cross-reaction with cashew. Moreover, those samples tested positive in a cashew-specific real-time PCR method [34]. In the last group of nine nut-free products, all the samples were negative for pistachio.

\section{Conclusions}

To the best of our knowledge, this is the first time a pistachio-specific recombinant antibody has been produced for detection of allergenic pistachio in food products and the first immunoassay for this purpose that is produced without animal immunization. It was demonstrated that the best biopanning strategies to recover pistachio-specific phage-dAbs were those using defatted pistachio protein extract as the target. The LOD of the pistachio assay developed is higher than that of other reported immunoassays [5,10,31]. The PVF4-dAb targets the pistachio basic subunit of the 11S globulin, and it is absent from cross reactions with the closely related cashew nuts, that are common in commercial ELISAs for pistachio detection.

Supplementary Materials: The following is available online at http://www.mdpi.com/2304-8158/9/9/1230/s1, Table S1: Peptides identified by MALDI-TOF/TOF from electrophoretic bands recognised by the PVF4 phage-dAb in the pistachio extract $(\mathrm{T})$ and in the chromatographic fractions 4, 6 and 8.

Author Contributions: Conceptualization-R.M. (Rosario Martín) and T.G.; Data curation-R.M. (Raquel Madrid); Formal analysis-R.M. (Raquel Madrid), A.G.-G., and T.G.; Funding acquisition-R.M. (Rosario Martín) and T.G.; Investigation-R.M. (Raquel Madrid); Methodology-R.M. (Raquel Madrid); Project administration-I.G. and T.G.; Resources-R.M. (Rosario Martín) and T.G.; Supervision-T.G.; Validation-R.M. (Raquel Madrid) and A.G.-G; Writing—original draft, R.M. (Raquel Madrid); Writing—review and editing, T.G. and R.M. (Rosario Martín). All authors have read and agreed to the published version of the manuscript.

Funding: This work was funded by Ministerio de Economía, Industria y Competitividad (MINECO, Spain) [AGL2017-84316-R] and by Comunidad de Madrid [Consejería de Educación S2018/BAA-4574]. Raquel Madrid and Aina García-García are recipients of pre- and postdoctoral contracts, respectively, from MINECO (Spain).

Acknowledgments: The proteomic analysis was performed in the Proteomic Unit of Complutense University of Madrid, a member of ProteoRed and is supported by grant PT17/0019, of the PE I+D+I 2017-2020, funded by ISCIII and ERDF. The Genomic analysis was performed in the Genomic Unit of Complutense University of Madrid.

Conflicts of Interest: The authors declare no conflict of interest.

\section{References}

1. Bulló, M.; Juanola-Falgarona, M.; Hernández-Alonso, P.; Salas-Salvadó, J. Nutrition attributes and health effects of pistachio nuts. Br. J. Nutr. 2015, 113, S79-S93. [CrossRef] [PubMed]

2. Tawde, P.D. Allergenic Cross-Reactivity between Cashew and Pistachio Nuts. M.S. Thesis, Florida State University, Tallahassee, FL, USA, 2004.

3. Willison, L.N.; Tawde, P.; Robotham, J.M.; Penney, R.M.; Teuber, S.S.; Sathe, S.K.; Roux, K.H. Pistachio vicilin, Pis v 3, is immunoglobulin E-reactive and cross-reacts with the homologous cashew allergen, Ana o 1. Clin. Exp. Allergy 2008, 38, 1229-1238. [CrossRef] [PubMed] 
4. Ahn, K.; Bardina, L.; Grishina, G.; Beyer, K.; Sampson, H.A. Identification of two pistachio allergens, Pis v 1 and Pis v 2, belonging to the 2 S albumin and 11S globulin family. Clin. Exp. Allergy 2009, 39, 926-934. [CrossRef] [PubMed]

5. Costa, J.; Silva, I.; Vicente, A.A.; Oliveira, M.B.P.P.; Mafra, I. Pistachio nut allergy: An updated overview. Crit. Rev. Food Sci. Nutr. 2019, 59, 546-562. [CrossRef] [PubMed]

6. World Health Organization and International Union of Immunological Societies, (WHO/IUIS). Allergen Search Results. Available online: http://www.allergen.org/search.php?allergensource=Pistacia+vera (accessed on 28 August 2020).

7. Sicherer, S.H.; Sampson, H.A. Food allergy: A review and update on epidemiology, pathogenesis, diagnosis, prevention, and management. J. Allergy Clin. Immunol. 2018, 141, 41-58. [CrossRef] [PubMed]

8. Reese, I.; Holzhauser, T.; Schnadt, S.; Dölle, S.; Kleine-Tebbe, J.; Raithel, M.; Worm, M.; Zuberbier, T.; Vieths, S. Allergen and allergy risk assessment, allergen management, and gaps in the European Food Information Regulation (FIR). Allergo. J. Int. 2015, 24, 180-184. [CrossRef]

9. Costa, J.; Fernandes, T.J.R.; Villa, C.; Oliveira, M.B.P.P.; Mafra, I. Advances in food allergen analysis. In Food Safety: Innovative Analytical Tools for Safety Assessment; Spizzirri, G., Cirillo, G., Eds.; John Wiley \& Sons, Inc.: Hoboken, NJ, USA, 2017; pp. 305-360. ISBN 9781119160588.

10. Liu, C.; Chhabra, G.S.; Sathe, S.K. Pistachio (Pistacia vera L.) detection and quantification using a murine monoclonal antibody-based direct sandwich enzyme-linked immunosorbent assay. J. Agric. Food Chem. 2015, 63, 9139-9149. [CrossRef]

11. López-Calleja, I.M.; de la Cruz, S.; González, I.; García, T.; Martín, R. Survey of undeclared allergenic pistachio (Pistacia vera) in commercial foods by hydrolysis probe real-time PCR. Food Control. 2014, 39, 49-55. [CrossRef]

12. European Parliament. European Union Directive 2010/63/EU of the European Parliament and of the Council of 22 September 2010 on the protection of animals used for scientific purposes. Off. J. Eur. Union 2010, L276, 33-79.

13. de la Cruz, S.; Cubillos-Zapata, C.; López-Calleja, I.M.; Ghosh, S.; Alcocer, M.; González, I.; Martín, R.; García, T. Isolation of recombinant antibody fragments $(\mathrm{scFv})$ by phage display technology for detection of almond allergens in food products. Food Control. 2015, 54, 322-330. [CrossRef]

14. Madrid, R.; de la Cruz, S.; García, A.; Martín, R.; González, I.; García, T. Detection of food allergens by phage-displayed produced antibodies. In Food Allergens. Methods in Molecular Biology; Lin, J., Alcocer, M., Eds.; Humana Press: New York, NY, USA, 2017; Volume 1592, pp. 109-128.

15. Bannas, P.; Hambach, J.; Koch-Nolte, F. Nanobodies and nanobody-based human heavy chain antibodies as antitumor therapeutics. Front. Immunol. 2017, 8. [CrossRef] [PubMed]

16. Hoogenboom, H.R.; de Bruine, A.P.; Hufton, S.E.; Hoet, R.M.; Arends, J.-W.; Roovers, R.C. Antibody phage display technology and its applications. Immunotechnology 1998, 4, 1-20. [CrossRef]

17. Lee, C.M.Y.; Iorno, N.; Sierro, F.; Christ, D. Selection of human antibody fragments by phage display. Nat. Protoc. 2007, 2, 3001-3008. [CrossRef]

18. Christ, D.; Famm, K.; Winter, G. Tapping diversity lost in transformations-in vitro amplification of ligation reactions. Nucleic Acids Res. 2006, 34, e108. [CrossRef]

19. Madrid, R.; de la Cruz, S.; García-García, A.; Alcocer, M.J.C.; González, I.; García, T.; Martín, R. Multimeric recombinant antibody ( $\mathrm{scFv}$ ) for ELISA detection of allergenic walnut. An alternative to animal antibodies. J. Food Compos. Anal. 2018, 67, 201-210. [CrossRef]

20. Sechi, S.; Chait, B.T. Modification of cysteine residues by alkylation. A tool in peptide mapping and protein identification. Anal. Chem. 1998, 70, 5150-5158. [CrossRef] [PubMed]

21. Tanha, J.; Xu, P.; Chen, Z.; Ni, F.; Kaplan, H.; Narang, S.A.; MacKenzie, C.R. Optimal design features of camelized human single-domain antibody libraries. J. Biol. Chem. 2001, 276, 24774-24780. [CrossRef] [PubMed]

22. Dreher, M.L. Pistachio nuts: Composition and potential health benefits. Nutr. Rev. 2012, 70, 234-240. [CrossRef]

23. Küçüköner, E.; Yurt, B. Some chemical characteristics of Pistacia vera varieties produced in Turkey. Eur. Food Res. Technol. 2003, 217, 308-310. [CrossRef]

24. Yang, J.; Liu, R.H.; Halim, L. Antioxidant and antiproliferative activities of common edible nut seeds. LWT-Food Sci. Technol. 2009, 42, 1-8. [CrossRef]

25. Ozdal, T.; Capanoglu, E.; Altay, F. A review on protein-phenolic interactions and associated changes. Food Res. Int. 2013, 51, 954-970. [CrossRef] 
26. Moo-Huchin, V.M.; Canto-Pinto, J.C.; Cuevas-Glory, L.F.; Sauri-Duch, E.; Pérez-Pacheco, E.; Betancur-Ancona, D. Effect of extraction solvent on the phenolic compounds content and antioxidant activity of Ramon nut (Brosimum alicastrum). Chem. Pap. 2019, 73, 1647-1657. [CrossRef]

27. Niccheri, F.; Real-Fernàndez, F.; Ramazzotti, M.; Lolli, F.; Rossi, G.; Rovero, P.; Degl'Innocenti, D. Human recombinant domain antibodies against multiple sclerosis antigenic peptide CSF114(Glc). J. Mol. Recognit. 2014, 27, 618-626. [CrossRef] [PubMed]

28. Waterhouse, A.; Bertoni, M.; Bienert, S.; Studer, G.; Tauriello, G.; Gumienny, R.; Heer, F.T.; de Beer, T.A.P.; Rempfer, C.; Bordoli, L.; et al. SWISS-MODEL: Homology modelling of protein structures and complexes. Nucleic Acids Res. 2018, 46, W296-W303. [CrossRef]

29. Sathe, S.K.; Teuber, S.S.; Roux, K.H. Effects of food processing on the stability of food allergens. Biotechnol. Adv. 2005, 23, 423-429. [CrossRef]

30. Benedé, S.; López-Expósito, I.; Molina, E.; López-Fandiño, R. Egg proteins as allergens and the effects of the food matrix and processing. Food Funct. 2015, 6, 694-713. [CrossRef]

31. Cho, C.Y.; Nowatzke, W.; Oliver, K.; Garber, E.A.E. Multiplex detection of food allergens and gluten. Anal. Bioanal. Chem. 2015, 407, 4195-4206. [CrossRef]

32. de la Cruz, S.; López-Calleja, I.; Martín, R.; González, I.; Alcocer, M.; García, T. Recent advances in the detection of allergens in foods. In Methods in Molecular Biology (Clifton, N.J.); Humana Press: New York, NY, USA, 2017; Volume 1592, pp. 263-295.

33. Boles, J.A. Thermal Processing. In Handbook of Meat Processing; Blackwell Publishing: Hoboken, NJ, USA, 2010; pp. 169-183. ISBN 9780813821825.

34. López-Calleja, I.M.; de la Cruz, S.; González, I.; García, T.; Martín, R. Development of real-time PCR assays to detect cashew (Anacardium occidentale) and macadamia (Macadamia intergrifolia) residues in market analysis of processed food products. LWT-Food Sci. Technol. 2015, 62, 233-241. [CrossRef]

(C) 2020 by the authors. Licensee MDPI, Basel, Switzerland. This article is an open access article distributed under the terms and conditions of the Creative Commons Attribution (CC BY) license (http://creativecommons.org/licenses/by/4.0/). 